\title{
Functional Reorganization of Visual Cortex Maps after Ischemic Lesions Is Accompanied by Changes in Expression of Cytoskeletal Proteins and NMDA and $\mathrm{GABA}_{\mathrm{A}}$ Receptor Subunits
}

\author{
Angelica Zepeda, ${ }^{1,3}$ Frank Sengpiel,,${ }^{3,4}$ Miguel Angel Guagnelli, ${ }^{1}$ Luis Vaca, ${ }^{2}$ and Clorinda Arias ${ }^{1}$ \\ ${ }^{1}$ Departamento de Biología Celular y Fisiología, Instituto de Investigaciones Biomédicas, ${ }^{2}$ Departamento de Biología Celular, Instituto de Fisiología Celular, \\ Universidad Nacional Autónoma de México, 04510-México, Distrito Federal, México, ${ }^{3}$ Max-Planck-Institut für Neurobiologie, 82152 München- \\ Martinsried, Germany, and ${ }^{4}$ Cardiff School of Biosciences, Cardiff University, Cardiff CF10 3US, United Kingdom
}

\begin{abstract}
Reorganization of cortical representations after focal visual cortex lesions has been documented. It has been suggested that functional reorganization may rely on cellular mechanisms involving modifications in the excitatory/inhibitory neurotransmission balance and on morphological changes of neurons peripheral to the lesion. We explored functional reorganization of cortical retinotopic maps after a focal ischemic lesion in primary visual cortex of kittens using optical imaging of intrinsic signals. After 1, 2, and 5 weeks postlesion (wPL), we addressed whether functional reorganization correlated in time with changes in the expression of MAP-2, GAP-43, GFAP, GABA receptor subunit $\alpha 1\left(\mathrm{GABA}_{\mathrm{A}} \alpha 1\right)$, subunit 1 of the NMDA receptor (NMDAR1), and in neurotransmitter levels at the border of the lesion. Our results show that: (1) retinotopic maps reorganize with time after an ischemic lesion; (2) MAP-2 levels increase gradually from 1wPL to $5 \mathrm{wPL}$; (3) MAP-2 upregulation is associated with an increase in dendritic-like structures surrounding the lesion and a decrease in GFAP-positive cells; (4) GAP-43 levels reach the highest point at 2wPL; (5) NMDAR1 and glutamate contents increase in parallel from $1 w P L$ to $5 \mathrm{wPL} ;(6) \mathrm{GABA}_{\mathrm{A}} \alpha 1$ levels increase from $1 \mathrm{wPL}$ to $2 \mathrm{wPL}$ but do not change after this time point; and (7) GABA contents remain low from 1wPL to 5wPL. This is a comprehensive study showing for the first time that functional reorganization correlates in time with dendritic sprouting and with changes in the excitatory/inhibitory neurotransmission systems previously proposed to participate in cortical remodeling and suggests mechanisms by which plasticity of cortical representations may occur.
\end{abstract}

Key words: plasticity; visual cortex; sprouting; maps; ischemia; injury; imaging techniques; cat; retinotopy; receptors; photochemical lesion; unmasking

\section{Introduction}

CNS as well as PNS lesions lead to functional deficits, yet recovery of the lost functions may occur over time. It has been proposed that restoration of functions after focal somatosensory and motor cortical damage (Nudo et al., 1996a; Rouiller et al., 1998a; Coq and Xerri, 1999; Rijntjes and Weiller, 2002) may rely, to some degree, on the reorganization of cortical maps. Cortical reorganization has been observed to involve either zones surrounding the lesion area (Castro and Borrell, 1995; Nudo et al., 1996a;

Received July 7, 2003; revised Nov. 25, 2003; accepted Nov. 25, 2003.

This work was supported by Consejo Nacional de Ciencia y Tecnologia (CONACYT) 36250M. F.S. was supported by the Max-Planck-Gesellschaft and the Medical Research Council. A.Z. was supported in part by Deutscher Akademischer Austausch Dienst, Graduierten-Kolleg München, and CONACYT, Mexico. We thank Tobias Bonhoeffer for support in the development of this project and for providing animal and optical imaging facilities, Gerhard Brändle for developing image analysis software, Beatriz Jimenez for assistance with confocal microscopy, and Patricia Ferrera, Iris Kehrer, and Frank Brinkmann for technical assistance. We are grateful to Federico Bermudez-Rattoni, Ricardo Tapia, and Ranulfo Romo for helpful comments on this manuscript.

Correspondence should be addressed to Dr. Clorinda Arias, Departamento de Biología Celular y Fisiología, Instituto de Investigaciones Biomédicas, Universidad Nacional Autónoma de México, Apartado Postal 70228, 04510 México, Distrito Federal, México. E-mail: carias@servidor.unam.mx.

DOI:10.1523/JNEUROSCI.3213-03.2004

Copyright $\odot 2004$ Society for Neuroscience $\quad 0270-6474 / 04 / 241812-10 \$ 15.00 / 0$
Rouiller et al., 1998a; Zepeda et al., 1999, 2003) or regions within the homologous contralateral cortex (Jones and Schallert, 1992; Jones et al., 1996; Nudo et al., 1996b; Dijkhuizen et al., 2003).

Reorganization of the visual cortex after focal lesions has been studied less until recently despite its clinical relevance. We have previously shown that visual cortex maps reorganize to a certain extent with time after an ischemic lesion (Zepeda et al., 2003), while Eysel and Schweigart (1999) have reported that single cells in the surrounding area of the lesion exhibit enlarged receptive fields. However, neurorepair mechanisms associated with such visual reorganization remain unknown.

Functional reorganization after central and peripheral lesions may rely on plasticity mechanisms involving modifications in the excitatory/inhibitory neurotransmission balance (Jones, 1993; Das and Gilbert, 1995a; Hagemann et al., 1998; Eysel and Schweigart, 1999; Arckens et al., 2000; Mittmann and Eysel, 2001) as well as in dendritic and axonal sprouting (Darian-Smith and Gilbert, 1994, 1995; Florence and Kaas, 1995; Stroemer et al., 1995; Li et al., 1998; Carmichael, 2003).

Dendritic and axonal regrowth have been associated with the expression of molecules such as MAP-2 and GAP-43, respec- 
tively. MAP-2 is a protein mainly found in soma and dendrites that plays a key role in maintaining neuronal architecture, in cellular differentiation, and in structural and functional plasticity (Sanchez et al., 2000). GAP-43 is mainly localized in growth cones. It is synthesized after cortical stroke, and its expression after nervous injury has been correlated with axonal regeneration (Stroemer et al., 1995; Li et al., 1998; Carmichael and Chesselet, 2002).

Studies addressing reorganization in the surrounding area of focal visual cortex lesions have also suggested neurochemical modifications involving a reduction in GABAergic inhibition and an increased glutamatergic response mediated by the NMDA receptor (Mittmann et al., 1994; Schiene et al., 1996; Eysel and Schweigart, 1999; Que et al., 1999a; Mittmann and Eysel, 2001). However, to our knowledge, a comprehensive temporal study exploring cortical reorganization after focal visual cortex lesions and its related morphological and biochemical modifications has not been performed. The goal of the current study was to induce a photochemical ischemic lesion in the primary visual cortex of kittens and correlate in time the observed functional reorganization with expression of MAP-2, GAP-43, neurotransmitter levels, and expression of subunit 1 of the NMDA receptor (NMDAR1) and $\mathrm{GABA}_{\mathrm{A}}$ receptor subunit $\alpha 1\left(\mathrm{GABA}_{\mathrm{A}} \alpha 1\right)$ at the border of the lesion.

\section{Materials and Methods}

The experiments were performed on 22 kittens ( $8-10$ weeks old); all procedures were performed in accordance with local government rules and the Society for Neuroscience Guide for the Care and Use of Laboratory Animals. Efforts were made to minimize animal suffering and to reduce the number of subjects used.

Before and after the lesion, kittens were housed in a laboratory environment with a $12 \mathrm{hr}$ artificial light/dark cycle. They lived within a colony of cats and did not receive any specific training or treatment at any time.

Optical imaging of intrinsic signals. Surgery and optical imaging techniques have been described in detail previously (Bonhoeffer and Grinvald, 1993, 1996). Animals $(n=2)$ were anesthetized intramuscularly with ketamine (20-40 mg/kg) and xylazine (Rompun; 2-4 mg/kg; Bayer, Leverkusen, Germany) and then intubated. They were placed in a stereotaxic frame and artificially respired with a mixture of $60 \% \mathrm{~N}_{2} \mathrm{O}$ and $40 \% \mathrm{O}_{2}$ with $0.7-1.5 \%$ halothane. Electrocardiogram, expired $\mathrm{CO}_{2}$, and body temperature were monitored throughout the experiment. A solution of $4 \%$ glucose in saline was infused intravenously at $3 \mathrm{ml} / \mathrm{kg} / \mathrm{hr}$ throughout the experiment. To prevent eye movements, the infusion solution was supplemented with the fast-acting muscle relaxant atracurium (Tracrium; $0.6 \mathrm{mg} / \mathrm{kg} / \mathrm{hr}$; GlaxoWellcome, Munich, Germany).

In the initial imaging session, the scalp was incised and retracted. A circular craniotomy was performed above area 17 (centered on P4, Horsley-Clarke coordinates), and a titanium chamber was cemented onto the skull. The chamber was filled with silicon oil and was sealed with a glass coverslip.

As described previously (Zepeda et al., 2003), animals were fitted with contact lenses to focus their eyes on a computer screen at a distance of 33 $\mathrm{cm}$. Retinotopic stimuli (VSG Series Three; Cambridge Research Systems, Rochester, UK) consisted of drifting high-contrast square wave gratings of 1 cycle/degree oriented at $0^{\circ}$ or $90^{\circ}$ within a $1^{\circ}$ wide horizontal aperture. Stimuli were presented in random order at 11 positions separated by $1^{\circ}$, from an elevation of $5^{\circ}$ above to $5^{\circ}$ below the horizontal meridian. In addition to retinotopic maps, orientation preference maps were obtained; visual stimuli consisted of high-contrast square wave gratings of $0.15-0.5$ cycles/degree, drifting back and forth at 2 cycles/sec and presented at 0 and $90^{\circ}$.

Each stimulus lasted $3 \mathrm{sec}$ (data consisted of five frames of $600 \mathrm{msec}$ duration) and was followed by a 9 sec interstimulus interval during which the next stimulus was displayed but remained stationary. For the analysis, the first frame (after the onset of drift) was discarded.
For intrinsic signal imaging, the cortex was illuminated with bandpass-filtered light of $707 \pm 10 \mathrm{~nm}$. Responses to visual stimulation were captured by a cooled slow-scan CCD camera focused $500 \mu \mathrm{m}$ below the cortical surface (ORA 2001; Optical Imaging, Germantown, NY).

A control optical imaging experiment was performed immediately before the photochemical lesion. A second recording session was conducted immediately after the lesion, and subsequent experiments were performed at 2 and 5 weeks postlesion (wPL).

After each but the final experiment, the chamber was half-filled with agar containing antibiotic (Paraxin; Bayer), and the rest of the chamber was filled with silicone oil and sealed with a glass coverslip. Anesthesia was suspended; kittens were allowed to recover and were then returned to their mother and littermates.

Retinotopic and orientation map analyses. Analysis of retinotopic representation was performed for two kittens, using Interactive Data Language software (Research Systems, Boulder, CO). We determined the cortical area for each stimulus position where a response above a fixed threshold (identical between stimuli and experiments) was observed and calculated the number of pixels for which an above-threshold response was obtained for neighboring stimulus positions. The extent of "overlap" in the responses to abutting stimuli was taken as a measure for the divergence in the retinocortical projection or, in other words, as an indicator of the aggregate receptive field size.

Analysis of orientation preference maps has been described in detail previously (Zepeda et al., 2003). Briefly, orientation maps were produced by dividing cortical responses to 0 and $90^{\circ}$ grating stimuli. Twelve-bit digitized camera images were range-fitted such that the $1.5 \%$ most responsive pixels were set to black and the least responsive to white. Signal amplitude was displayed on an eight-bit gray scale.

Photochemical lesion. For inducing the lesion, we used the photochemical lesion technique initially described by Watson et al. (1985), with some variations. Animals were anesthetized as described above. The scalp was incised and retracted, a circular craniotomy was performed above area 17 (centered on P4, Horsley-Clarke coordinates), and the dura was removed from the area to be lesioned. The cortical surface was carefully cleared of any traces of blood using Sugi sterile swabs (Kettenbach, Eschenburg, Germany). A krypton/argon $514 \mathrm{~nm}$ laser beam (Ion Laser Technology, Salt Lake City, UT) light guide positioned $\sim 5 \mathrm{~cm}$ above V1 was directed toward the area of the cortex where the ischemic lesion was to be produced. Rose Bengal dye (10 mg/kg; Sigma, St. Louis, MO) was injected over a 2 min interval through the femoral vein; the cortex was illuminated simultaneously and for the next $12 \mathrm{~min}$. The parameters ensured vascular occlusion in an area of $\sim 3 \mathrm{~mm}$. In those animals not used for optical imaging, the titanium chamber was replaced by a glass coverslip that fitted in the craniotomy. The coverslip was cemented onto the skull, and a plastic ring ( $1 \mathrm{~cm}$ height) was cemented on top of it. The skin was sutured, leaving a window in which the coverslip and the plastic ring had been placed. This enabled us to monitor the lesion area at all time points. After different survival times postlesion (1,2, and 5 weeks), animals were killed.

Histology and immunohistochemistry. Animals ( $n=10$; three lesioned per time point and one nonlesioned) received an overdose of barbiturate and were perfused transcardially with $0.9 \%$ saline, followed by chilled $2 \%$ paraformaldehyde fixative and $0.18 \%$ picric acid in phosphate buffer. Brains were removed, postfixed at $4^{\circ} \mathrm{C}$ for $4 \mathrm{~d}$, and then successively transferred to sucrose solutions (up to $30 \%$ ). Sequential 14 and $30 \mu \mathrm{m}$ coronal sections were cut at the level of the lesion on a cryostat. Thirtymicrometer sections were mounted on gelatin-covered slides and processed for cresyl violet (Nissl) staining. Fourteen-micrometer sections were mounted on silane (g-methacryloxypropyltrimethoxysilane; Sigma)-covered slides and processed for double immunofluorescence. Briefly, slides containing $14 \mu \mathrm{m}$ sections were placed in a vacuum chamber for $20 \mathrm{~min}$ before and after mounting the sections. A layer of Glyco (artwork glue; Distribuidora Rodin, Mexico City, Mexico) surrounding the sections was applied. This would act as a barrier for the solutions bathing the sections. Once the glue was dry, sections were washed three times for $10 \mathrm{~min}$ in PBS-Triton $(0.3 \%)$ and incubated in normal horse serum (1:25; Vector Laboratories, Burlingame, CA) in PBS-Triton $(0.3 \%)$ for $2 \mathrm{hr}$. Afterward, they were incubated in rabbit anti-cow GFAP 
(1:1000; DAKO, Carpinteria, CA) and monoclonal anti-MAP2 (1:250; Chemicon, Temecula, CA) for $12 \mathrm{hr}$ in a humid chamber. Sections were washed three times for $10 \mathrm{~min}$ in PBS-Triton $(0.3 \%)$ and then incubated in fluorescein-conjugated goat anti-rabbit (1:250; Zymed, San Francisco, CA) (excitation, $494 \mathrm{~nm}$; emission, $519 \mathrm{~nm}$; green fluorescence) and Cy5 goat anti-mouse (1:40; Jackson ImmunoResearch, West Grove, PA) (excitation, $650 \mathrm{~nm}$; emission, $670 \mathrm{~nm}$; blue fluorescence) secondary antibodies for $2 \mathrm{hr}$ in a humid chamber. Sections were washed three times for 10 min in PBS-Triton (0.3\%) and then incubated in Radiant Red (1:100; Bio-Rad, Hercules, CA) (excitation $596 \mathrm{~nm}$, emission, $615 \mathrm{~nm}$; red fluorescence) for $10 \mathrm{~min}$ in a humid chamber. Afterward, they were washed three times for $10 \mathrm{~min}$ in PBS and covered with fluorescent mounting medium (DAKO). Cross-reactivity was excluded by appropriate controls: control sections were incubated in the same solutions as experimental sections but without primary antibodies. Incubation with secondary antibodies was performed as described for experimental sections. Tissue processed in the absence of primary antibodies showed no immunostaining.

Confocal microscopy reconstructions and density measurements. Sections were analyzed with a confocal laserscan microscope (Bio-Rad). For each subject ( $n=3$ per time point), we analyzed six sections of tissue corresponding to the beginning, middle, and end of the lesion. Individual images $(\sim 80)$ from the lesion zone were acquired; 10 optical sections from each image were acquired. Confocal images were imported into the Confocal Assistant Program version 4.02 (designed by Todd Clark Brelje, University of Minnesota, Minneapolis, $\mathrm{MN}$ ); each image was projected in the $\mathrm{z}$ plane (10 optical sections), and maximal values of pixels were integrated to produce single images containing the information of the 10 optical sections. Projected images were then imported to Corel Photopaint 10 (Corel, Ottawa, Ontario, Canada), and the center and surrounding area of the lesions were reconstructed.

Measurements of optical density of MAP-2 from confocal images. Areas of $1.5 \mathrm{~mm}$ in height and $2 \mathrm{~mm}$ width immediately adjacent to the pyknotic area were extracted from the reconstructed lesion area (see Fig. 3) at all postlesion times. The images corresponding to the blue channel (MAP-2) were used to measure the number of pixels in the $1.5 \times 2 \mathrm{~mm}$ area for cortical layers IV-VI. Measurements were done using Igor Pro 4.02 (Wavemetrics, Lake Oswego, OR); values (pixels/micrometer) are reported for all postlesion times. Cortical layers were identified following the criteria reported by Peters and Yilmaz (1993).

Measurements of MAP-2-positive somata from confocal images. Immunopositive MAP-2 somata were counted in an area of $2 \mathrm{~mm}$ in height and $1 \mathrm{~mm}$ width immediately adjacent to the pyknotic area from all animals using Igor Pro 4.02 (Wavemetrics).

Volumetric measurements and reconstruction of the lesion. All Nissl sections containing an area of photochemically damaged tissue were used to calculate the volume of the lesion. Nissl sections were $30 \mu \mathrm{m}$ thick and were separated by $45 \mu \mathrm{m}$. Serial sections were placed under a transilluminator (Northern Light, Quebec, Canada), and images of the lesion were acquired through a CCD camera (NEC, Santa Clara, CA) attached to a computer. The area of the lesion in each Nissl section was measured using NIH Image software (Scion, Frederick, MD), and total lesion volume $(\mathrm{Vol})$ was calculated as:

$$
V o l=\Sigma^{n}[(A s)(T)+(A s)(K)]_{i},
$$

where, $A s$ is the area of lesion in one Nissl section, $T$ is the thickness of the Nissl section $(30 \mu \mathrm{m}), K$ is the tissue separating adjacent Nissl sections, and $n$ is the number of sections that contain the lesion.

These measurements were done for every brain, and the means \pm SEM were calculated. One-way ANOVA was performed to assess differences between groups sacrificed at different time points.

Electrophoresis and immunoblotting. Animals $(n=10$; three lesioned per time point and one nonlesioned) were decapitated, and brains were removed, submerged in chilled phosphate buffer $(0.1 \mathrm{~m}$ for $1 \mathrm{~min})$, transferred to liquid nitrogen, and stored at $-70^{\circ} \mathrm{C}$. Guided by the visible lesion area (pale region) on the surface of the brain, coronal sections ( 120 $\mu \mathrm{m})$ were cut in a cryostat at $-20^{\circ} \mathrm{C}$. The lesion area from each section was then extracted using a suction pipette. In every case, the extracted tissue contained the center of the lesion and $2 \mathrm{~mm}$ of surrounding tissue (see Fig. 4A). Alternate sections were used for immunoblotting and HPLC (see below). Tissue samples were homogenized in lysis buffer containing Tris- $\mathrm{HCl}(0.05 \mathrm{M}, \mathrm{pH} 7.5), \mathrm{NaCl}(0.15 \mathrm{~m}), \mathrm{NP}-40$ (1\%), and sodium deoxycholate $(0.5 \%)$ supplemented with a protease inhibitor mixture (Complete; EDTA free; Roche, Mannheim, Germany). Tissue extracts were analyzed by using SDS-PAGE. Samples (50 $\mu \mathrm{g}$ of protein/ well) diluted in Laemmli's (1970) solution were run under reducing conditions ( $5 \% \beta$-mercaptoethanol) through $0.75 \mathrm{~mm}$ thick, $10 \%$ gels (Miniprotean II; Bio-Rad) at $50 \mathrm{~mA}$ constant current for $2 \mathrm{hr}$. Prestained molecular weight markers (Amersham Biosciences, Piscataway, NJ) were used to determine the relative mobility of proteins. After the electrophoresis, the gels were equilibrated in transferring buffer ( $25 \mathrm{~mm}$ Tris, $192 \mathrm{~mm}$ glycine, and 20\% methanol) for $15 \mathrm{~min}$, and the proteins were electro-transferred to nitrocellulose sheets (Bio-Rad) at $200 \mathrm{~mA}$ for $1 \mathrm{hr}$ at $4^{\circ} \mathrm{C}$. The membranes were blocked with nonfat milk (5\%) in TBS (20 $\mathrm{mm}$ Tris and $135 \mathrm{~mm} \mathrm{NaCl}$ ) for $2 \mathrm{hr}$ at room temperature, washed three times for $5 \mathrm{~min}$ in TBS containing Tween 20 (0.05\%) (TTBS), and then incubated with one of the following monoclonal antibodies: antiNMDAR1 (1:400; PharMingen, San Diego, CA), anti-GABA $\alpha 1$ (1:600; Santa Cruz Biotechnology, Santa Cruz, CA), anti-MAP2 (1:400; Chemicon), anti-NeuN (1:500; Chemicon), or a polyclonal anti-GAP43 (1:500; Chemicon) overnight at $4^{\circ} \mathrm{C}$. Membranes were washed three times in TTBS and incubated with a goat anti-mouse secondary antibody conjugated with biotin (1:1000; Vector Laboratories) for $2 \mathrm{hr}$ at room temperature, washed three times in TTBS, and then incubated in avidin-biotin (1:200; Vector Laboratories) for $30 \mathrm{~min}$ at room temperature. Finally, after washing the membranes with TTBS four times for 5 min each, immunolabeled bands were identified by using a chemiluminescencebased detection kit according to the protocol suggested by the manufacturer (ECL; Amersham Biosciences, Buckinghamshire, UK). Densitometric analysis of bands was performed using NIH Image for Windows 2000 (Scion). One-way ANOVA was performed to establish differences in contents of proteins evaluated at different time points after the lesion.

HPLC. To determine total contents of amino acids in the lesion area and its surrounding area, $120 \mu \mathrm{m}$ coronal sections were obtained as described above and processed for HPLC. Two to three sections per animal were weighed ( $\sim 4 \mathrm{mg}$ wet weight/section). Sections containing the center of the lesion and $2 \mathrm{~mm}$ of surrounding tissue were homogenized in $0.2 \mathrm{ml}$ of $0.7 \%$ perchloric acid (see Fig. $4 A$ ). After the precipitated protein was sedimented by centrifugation, the extracts were neutralized with $1 \mathrm{M} \mathrm{KOH}$, and potassium perchlorate was spun down. Aliquots of the extracts were derivatized automatically with o-phthalaldehyde (Geddes and Wood, 1984) in an automatic sampler (Waters, Milford, MA). Twenty microliters of the sample were injected automatically into a HPLC system. An ODS column $(25 \times 4 \mathrm{~mm}$ internal diameter; Supelco, Bellefonte, PA) was used, and the column effluent was monitored with a fluorescence detector, at $340 \mathrm{~nm}$ excitation wavelength and $418 \mathrm{~nm}$ emission wavelength. The mobile phase was phosphate buffer ( $60 \mathrm{~mm}), \mathrm{pH} 6.65$, in one line and $46 \%$ phosphate buffer, $18 \%$ methanol, $22 \%$ acetonitrile, and $14 \%$ isopropanol in the other line and was run at $1 \mathrm{ml} / \mathrm{min}$. Obtained results were compared with standard samples processed similarly. Results were expressed as picomoles of wet tissue per milligram, and differences between groups were evaluated with one-way ANOVA.

\section{Results}

\section{Photochemically induced cortical lesion}

Using the photochemical procedure described previously (Zepeda et al., 2003), we obtained reproducible lesions in the visual cortex of anesthetized animals. The lesion area was easily identified in the blood vessel pattern immediately after the lesion procedure was completed and was characterized macroscopically by a pale area $\left(\sim 3 \mathrm{~mm}^{2}\right)$ containing occluded blood vessels (Fig. 1 $A$ ).

\section{Retinotopic cortical maps reorganize in time after the photochemical lesion}

Immediately after the lesion, optical imaging of intrinsic signals revealed an area of cortex devoid of visually driven activity, which 
was very similar in size $\left(\sim 3 \mathrm{~mm}^{2}\right)$ to the area identified macroscopically as ischemic. To evaluate overall responsiveness to visual stimulation in the exposed cortical area, orientation preference maps were first obtained (Fig. $1 B$ ) as reported previously (Zepeda et al., 2003). To assess retinotopic representation of visual space of the cortical surface before and after the lesion, grating stimuli oriented at 0 or $90^{\circ}$ were presented within a $1^{\circ}$ wide horizontal aperture, the position of which was varied in $1^{\circ}$ steps. Typically, two such stimuli presented in adjacent positions (covering a total of $2^{\circ}$ of visual space) elicited responses from almost the entire exposed visual cortex (Fig. 1C,D). Before the lesion, the overlap in cortical surface area responding to two adjacent retinotopic stimuli was, on average, $0.755 \mathrm{~mm}^{2}$ (Fig. $1 C-E$, top row, $F)$. Because most of this overlap was within the lesion zone, it was
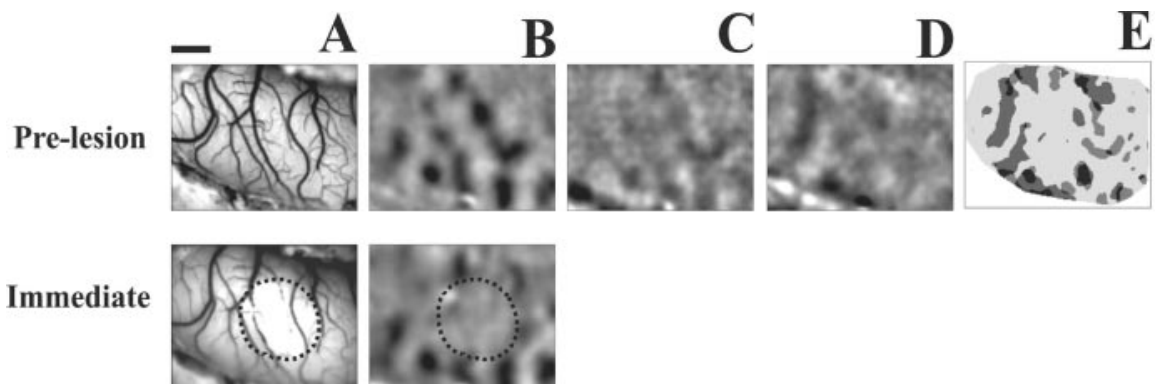

2wPL
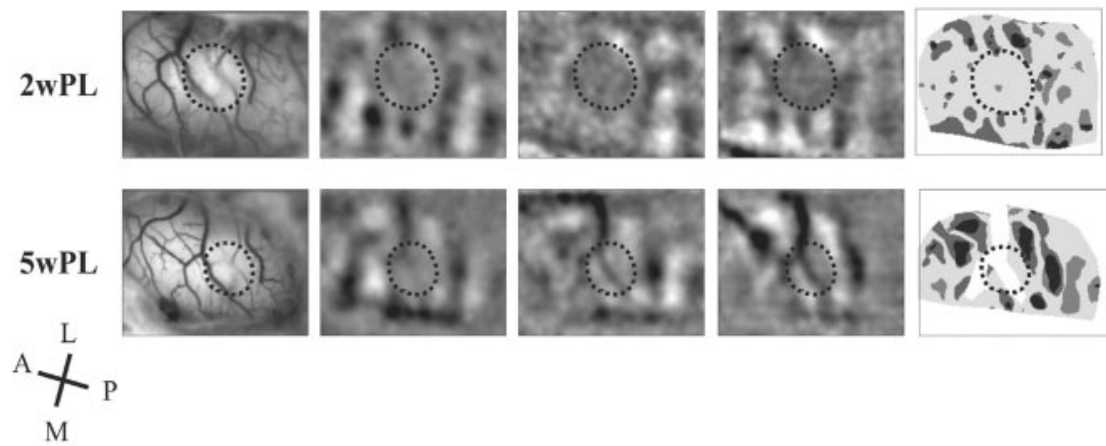

$\mathrm{M}$

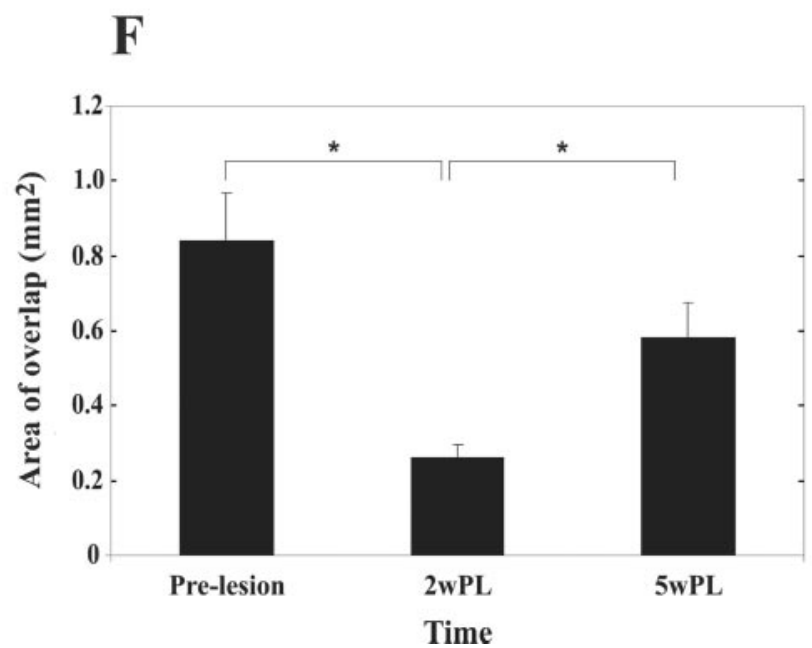

Figure 1. Retinotopic map reorganization after an ischemic lesion. $A$, Blood vessel pattern. $B$, Iso-orientation maps in response to gratings of $0^{\circ}$. C, Retinotopic map in response to a $1^{\circ}$ wide stimulus oriented at $0^{\circ}$. $D$, Retinotopic map in response to $1^{\circ}$ wide stimulus oriented at $0^{\circ}$, adjacent to the stimulus presented in C. $E$, Overlap between responses in $C$ and $D$ : light gray domains correspond to active zones in $C$, dark gray domains correspond to active zones in $D$, and black zones correspond to active areas in both $C$ and $D$, the "overlap." Note that the overlapping area fully recovers after 5 WPL. Orientation of the imaged cortical area is shown ( $A$, anterior; $P$, posterior; $M$, medial; $L$, lateral). $F$, Area of overlap $\left(\mathrm{mm}^{2}\right)$ in response to adjacent stimuli. Values represent the mean \pm SEM. Asterisks denote significant differences ( $t$ test; $p<0.05$ ) between groups. Scale bar, $1 \mathrm{~mm}$.
Functional reorganization is associated with modifications in cellular markers of morphological plasticity

To study morphological modifications of the ischemic lesion and its surrounding area over time, we performed a triple labeling of MAP-2, GFAP, and nuclei. This allowed us to establish a correlation between neuronal death, the gliotic scar process, and the presence of dendritic structures in the surrounding area of the ischemic lesion. Figure $2 A$ shows the reconstruction of layers I-VI from a control animal. Control tissue showed the following characteristics: (1) GFAP immunoreactivity was exclusively seen for astrocyte-like cells; (2) GFAP-immunopositive cortical astrocytes were mainly protoplasmic, whereas white matter astrocytes were fibrous; (3) the glial density was more or less uniform across all cortical layers, except for layers I and II, where the glia limitans is found; (4) MAP-2 was found surrounding exclusively the soma of neurons and in dendritic-like processes; (5) no colocalization of GFAP and MAP-2 was observed; and (6) MAP-2-immunopositive fibers were differentially distributed along cortical layers (Peters and Yilmaz, 1993). Given that MAP-2 is abundant in layers I and II but very scarce in white matter, we used the presence of MAP-2 in layers I and II as a positive control and the absence of MAP-2 in white matter as a negative control of immunoreactivity in all experiments.

Figure 2, $B-D$, shows reconstructions of $\sim 80$ confocal images obtained at 1,2 , and 5wPL. Morphology of the lesion shows that in all cases the lesion was successfully induced in cortical area 17 . Triple labeling histochemistry revealed at all time points a well delimited conical-shaped lesion extending from layers I to VI characterized by a body of pyknotic nuclei surrounded mainly by anisomorphic fibrous astrocytes. MAP-2-immunopositive fibers were clearly observed in control sections (Figs. 2A, 3A) but were absent in the surrounding area of the lesion center in sec- 
A

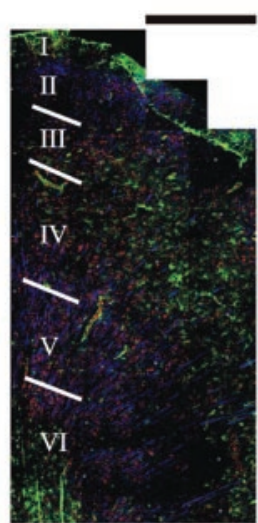

C

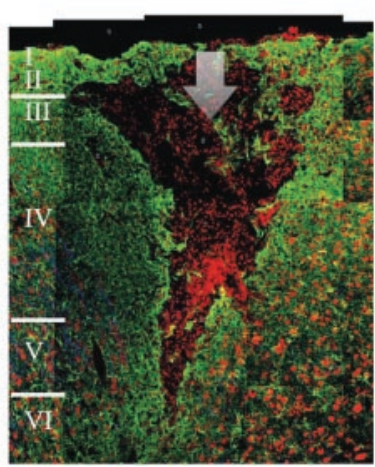

B

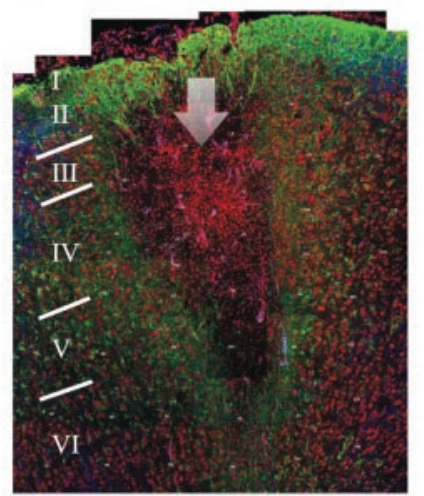

D

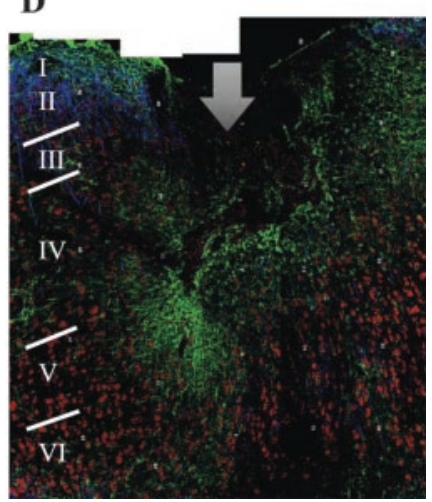

Figure 2. Triple inmunohistochemistry and confocal microscopy reconstructions of the lesion area from a coronal section. The section belongs, in every case, to the largest area of the lesion in the anteroposterior coordinate. Each image ( $~ 86$ per section) was projected in the $z$ plane (10 optical sections), and maximal values of pixels were integrated to produce single images containing the information of the 10 optical sections; images were then assembled to reconstruct the coronal section. Red, Nuclei; green, GFAP; blue, MAP-2. A section from a control cat $(A)$ and sections from cats killed at $1 w P L(B), 2 w P L(C)$, and 5 wPL $(D)$ are shown. Each image is representative of three different animals per time point. Cortical layers are indicated to the left. The arrow points at the center of the lesion. Scale bar, $500 \mu \mathrm{m}$.

tions obtained at $1 \mathrm{wPL}$ (Figs. $2 B, 3 B$ ). After 2 and $5 \mathrm{wPL}$, MAP-2 density of immunopositive fibers gradually increased (Figs. 2C,D, $3 C, D)$. The figure clearly shows that the size of lesion diminishes over time; this observation was corroborated by the volumetric analysis from serial Nissl-stained sections (data not shown) that revealed a lesion volume of $\left(\mathrm{mm}^{3} \pm \mathrm{SEM}\right) 2.65 \pm 0.21$ at $1 \mathrm{wPL}$, $0.90 \pm 0.12$ at $2 \mathrm{wPL}$, and $0.40 \pm 0.08$ at $5 \mathrm{wPL}$ (Redecker et al., 2002; Zepeda et al., 2003).

Figure $3 \mathrm{~A}$ shows the magnification of layers IV-VI from a control subject (area 17) and from areas immediately adjacent to the lesion center in animals killed at 1,2 , and $5 \mathrm{wPL}$ (Fig. $3 B-D$ ). In sections from lesion animals, pyknotic nuclei were found to aggregate in a region devoid of GFAP- or MAP-2immunopositive cells (center of the lesion) and were also found in the dense glial scar surrounding the center (Fig. $3 B-D$ ). The area occupied by pyknotic nuclei diminished over time in all subjects. At no time point did we detect the presence of fragmented nuclei that have been associated with apoptotic processes.

Reconstructions from the lesion area show that both density and distribution of GFAP and MAP-2 changed with time. After $1 w P L$, a dense region of anisomorphic astroglia was found around the center of pyknotic nuclei. In areas adjacent to the dense glial scar, scattered isomorphic protoplasmic astrocytes

A

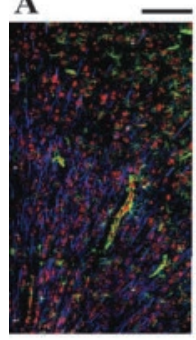

C

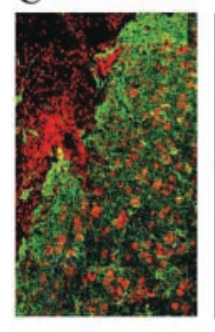

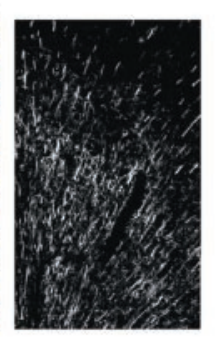

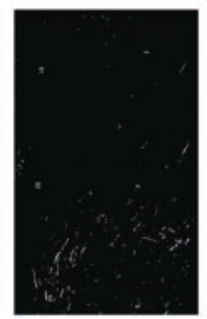

B

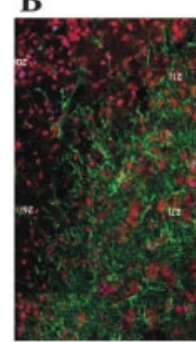

D

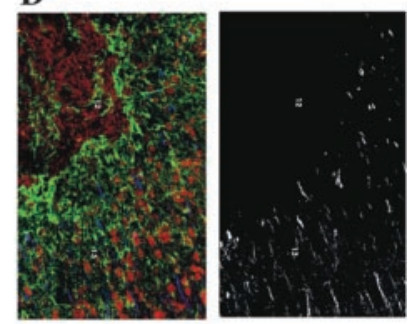

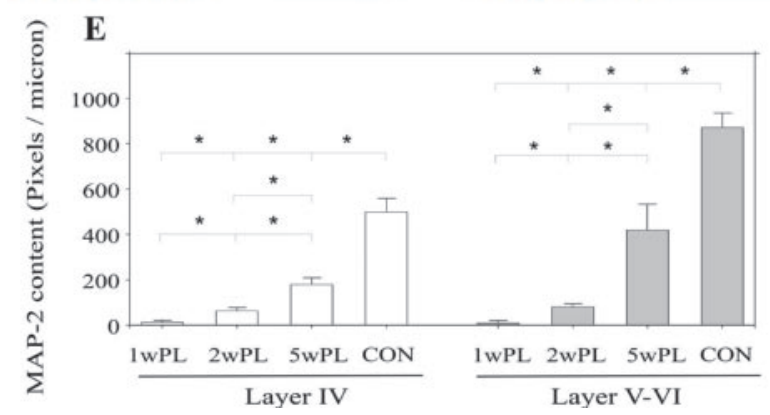

Figure 3. Increase in time of MAP-2-IR fibers within the gliotic area surrounding the lesion center. Red, Nuclei; green, GFAP; blue, MAP-2. In black and white images to the right of each color image, the corresponding blue channel was isolated and coded in gray scale for clarity. $A$, Control; $B, 1 w P L ; C, 2 w P L ; D, 5 w P L$. Notice the absence of MAP-2 after $2 w P L$ ( $B$, right) and the presence of dendritic structures at $5 \mathrm{WPL}(D$, right). $E$, 0ptical density of MAP-2 contents in

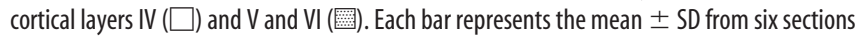
containing the beginning, middle, and end of the lesion from three different animals, measured in an area adjacent to the lesion as described in Materials and Methods. The asterisk denotes a significant difference $(p<0.05)$ between groups. CON, Control. Scale bar, $500 \mu \mathrm{m}$.

were found. No MAP-2-immunopositive structures could be detected in the center of the lesion or within the glial scar in any cortical layer (Figs. 2B, 3B,E). Only at a distance of $1 \mathrm{~mm}$ from the center of the lesion, MAP-2 could be found surrounding intact somata and forming dendrite-like structures.

After 2wPL, the glial scar still looked dense, but few dendritic structures were found within the scar at a distance of $340 \pm 117$ $\mu \mathrm{m}$ from the center of the lesion (Figs. $2 C, 3 C, E$ ). At $5 \mathrm{wPL}$, the density of GFAP-immunopositive cells was considerably decreased in comparison with 1 and $2 \mathrm{wPL}$, and the lesion area was obviously smaller (Figs. 2D, 3D,E). At this time point, a higher density of dendritic structures in comparison with $2 \mathrm{wPL}$ was found within the gliotic scar in all cortical layers (Fig. 3D,E). Dendritic structures were found as close as $60 \pm 5 \mu \mathrm{m}$ from the lesion center (the area of pyknotic nuclei). In no case were MAP2-immunopositive structures found within the center of the lesion. In parallel with the occurrence of MAP-2, functional maps also reappeared closer to the lesion with time. At 2 and 5wPL, functional maps were found at $516 \pm 140 \mu \mathrm{m}$ and $317 \pm 54 \mu \mathrm{m}$ from the lesion center, respectively. 
A

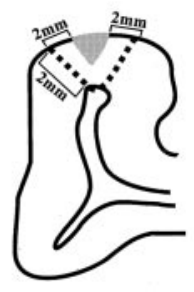

B

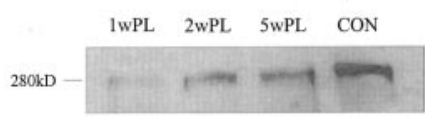

MAP-2

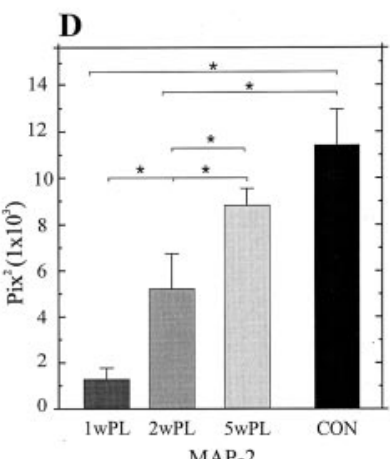

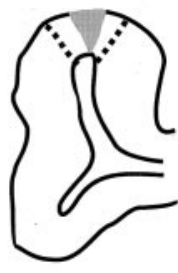

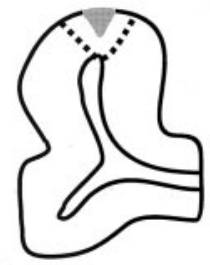

C

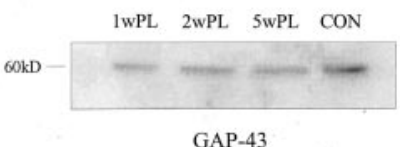

E

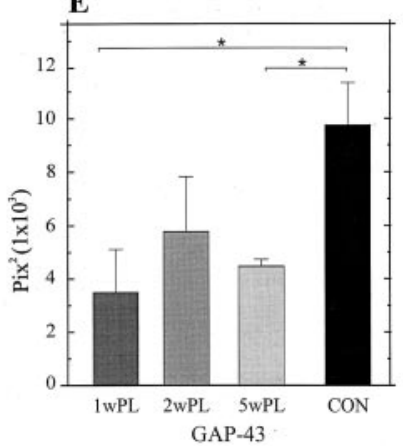

Figure 4. Time-dependent modifications in MAP-2 and GAP-43 contents in the center and surrounding area of the lesion. $A$, Schematics of $\mathrm{V} 1$ coronal sections from near the anterior border, the center, and the posterior border of the lesion (gray triangles). The dotted lines show the limits of tissue extracted with the suction pipette. Extracted tissue included the lesion center and $2 \mathrm{~mm}$ lateral and ventral to the borders of the lesion. Representative Western blots of MAP-2 ( $B$ ) and GAP-43 ( $C$ ) obtained from homogenates of the lesion tissue depicted in $A$ are shown. Each Western blot was performed two times on three different animals. The histograms show a densitometric quantitative analysis from MAP-2 (D) and GAP-43 (E). Data are the mean \pm SEM of three animals per time point. The asterisk denotes a significant difference $(p<0.05)$ between groups.

\section{Differential modifications in time in the contents of MAP-2 and GAP-43}

Western blots of MAP-2 show that at 1wPL the protein level in areas adjacent to the lesion dropped by $89 \%$ with respect to control levels (Fig. $4 B, D$ ). However, a clear recovery of protein levels toward control values was observed at 2 and $5 \mathrm{wPL}$. Thus, by 2 and $5 \mathrm{wPL}$, protein levels had recovered by 46 and $77 \%$, respectively, with respect to control (Fig. $4 B, D$ ). One-way ANOVA showed significant differences between control and 1wPL $(p<0.01)$ and control and $2 \mathrm{wPL}(p<0.05)$ but not between control and 5wPL (Fig. 4D). This recovery parallels the observed increase in the occurrence and density of MAP-2-positive structures in the area surrounding the lesion.

At 1wPL, GAP-43 levels were also reduced to $35 \%$ of control levels. By $2 \mathrm{wPL}$, protein levels recovered to $59 \%$ with respect to the control (Fig. 4C,E). However, in contrast to MAP-2, GAP-43 levels did not continue to increase toward control values. Thus, by $5 \mathrm{wPL}$, protein levels were at just $46 \%$ with respect to the control, 13\% less than 2wPL levels (Fig. 4C,E). One-way ANOVA showed that GAP-43 levels were significantly reduced at $1 \mathrm{wPL}$ $(p<0.05)$, but at 2 wPL no differences were detected when compared with control values. By 5wPL, GAP-43 levels had dropped again, and a significant difference was found when compared with control $(p<0.05)$ (Fig. $4 E)$.
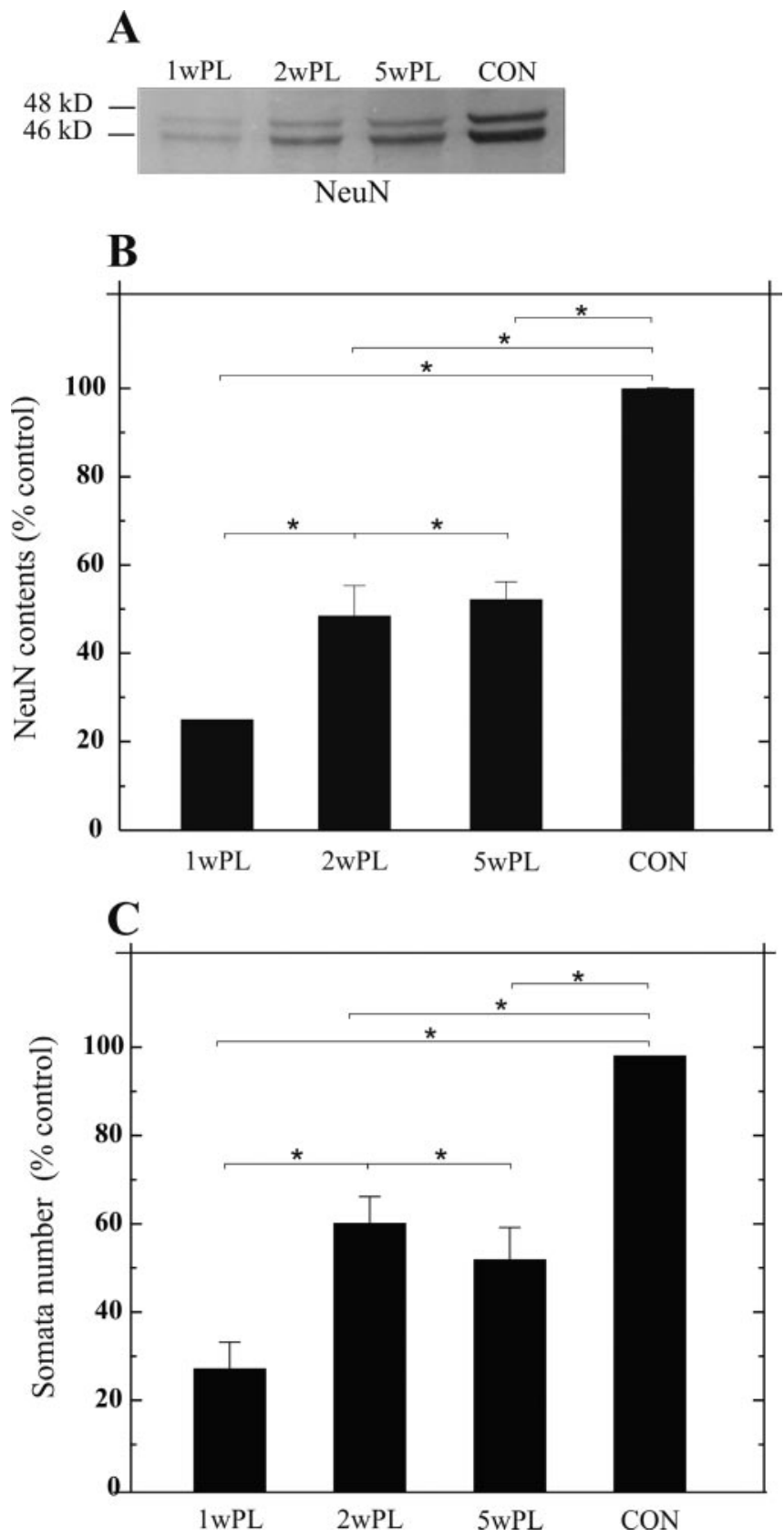

Figure 5. NeuN contents in the center and surrounding area of the lesion. $A$, Representative Western blots of NeuN obtained from homogenates of the lesion tissue as indicated in Figure $4 \mathrm{~A}$ $(n=3)$. B, Histogram showing results of the densitometric analysis of NeuN blots. C, Density of neuronal somata in a $2 \mathrm{~mm}$ zone surrounding the lesion core. The asterisk denotes a significant difference $(p<0.05)$ between groups.

\section{Contents of the neuronal-specific nuclear protein $\mathrm{NeuN}$ and} MAP-2-positive somata through time

To evaluate the density of neuronal cells in the surrounding area of the lesion core through time, we analyzed the expression of the neuronal-specific nuclear antigen $(\mathrm{NeuN})$ by Western blot (Mullen et al., 1992) (Fig. 5A,B) and additionally counted MAP2 -positive somata in the surrounding area of the lesion. We found that NeuN diminishes substantially after 1wPL and increases after $2 \mathrm{wPL}$ (Fig. 5B). Importantly, the values obtained after 2 and 5wPL are not significantly different and they do not reach control levels (nonlesion subjects) (Fig. 5B). The NeuN results show a strong correlation with the density of MAP-2-positive somata (Fig. $5 C$ ). Together, these two independent measures demonstrate that the num- 
ber of neurons in the surrounding area of the lesion does not increase significantly between 2 and 5wPL, when significant increases in the density of MAP-2-positive fibers occur.

\section{Functional reorganization is}

differentially associated with changes in NMDAR1, GABA $A_{A} \alpha 1$, glutamate, and GABA levels

Immunoblotting analysis of receptor proteins show that at 1wPL NMDAR1 subunit was $84 \%$ below control. However, protein levels increased subsequently, such that by 2 and 5wPL NMDAR1 subunit levels had recovered to 46 and $77 \%$, respectively, of the control (Fig. 6A,C). One-way ANOVA showed significant differences $(p<0.01)$ between control and all time points including $5 \mathrm{wPL}$, despite the clear recovery in NMDAR1 levels observed by that point (Fig. 6C).

Total contents of different amino acids as measured from HPLC from control animals and animals killed after 1,2, and 5wPL are shown in Table 1. Significant changes between 1 and 5wPL were only detected for the excitatory amino acids, aspartate, and glutamate. Glutamate levels were diminished by $74 \%$ at $1 w P L$ with respect to control (Fig. $6 E$; Table 1). This value was not significantly different from the value of $75 \%$ obtained at 2 wPL. However, total contents of glutamate continued to increase toward control values such that at $5 \mathrm{wPL}$ a statistically significant rise of $90 \%(p<0.05)$ was observed when compared with 1wPL (Fig. 6 E).

Contents of $\mathrm{GABA}_{\mathrm{A}} \alpha 1$ subunit showed a highly significant $(p<0.01)$ decrease of $66 \%$ at $1 \mathrm{wPL}$ with respect to control values. At 2 and $5 \mathrm{wPL}$, protein levels almost reached control values, being 90 and $78 \%$, respectively, when compared with control (Fig. $6 B, D$ ); these two values were not statistically different from each other or from control values.

Total contents of GABA as measured from HPLC were diminished by 74,72 , and $35 \%$ at 1,2 , and $5 \mathrm{wPL}$, respectively, when compared with control values (Fig. 6F; Table 1). One-way ANOVA showed that GABA levels were significantly reduced $(p<0.05)$ at all time points when compared with control values and that a slight increase in amino acid contents from 1 to $5 \mathrm{wPL}$ was not significant (Fig. 6F).

Our data demonstrate that NMDAR1 and glutamate levels upregulate strongly and in parallel over time after the photochemical lesion, whereas the $\mathrm{GABA}_{\mathrm{A}} \alpha 1$ receptor subunit exhibits an upregulation and GABA levels remain low throughout the explored period of time.

\section{Discussion}

In the present study, we report that cortical retinotopic maps reorganize after an ischemic lesion. Plasticity of functional maps
B

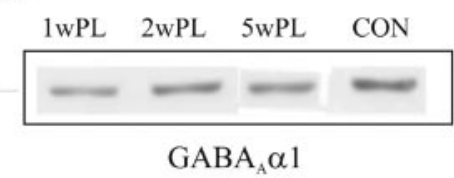

D
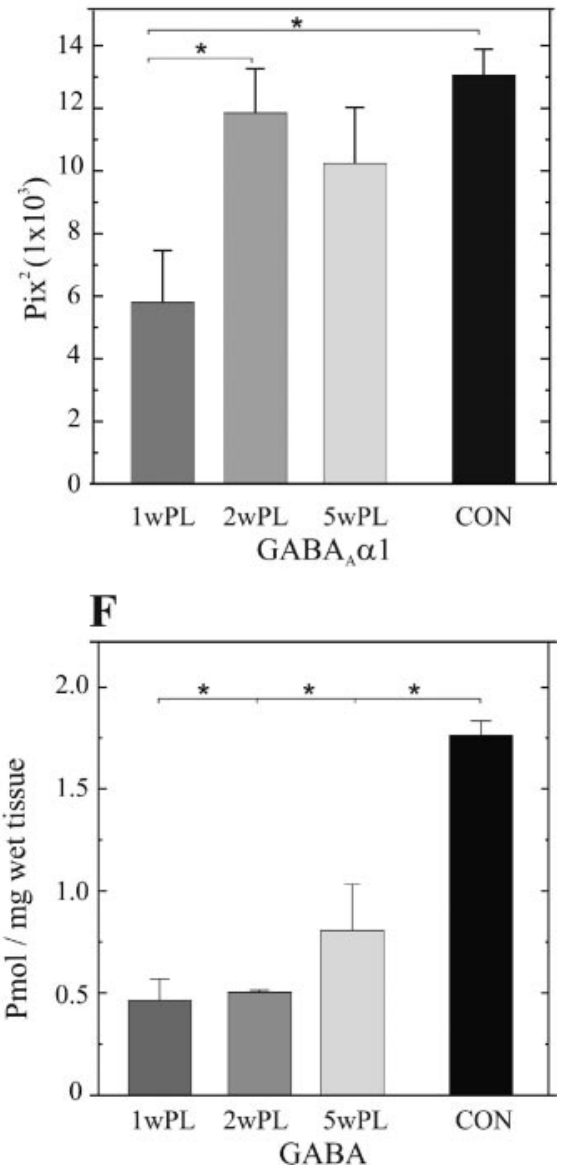

Figure 6. Time-dependent modifications in NMDAR1 and $\mathrm{GABA}_{A} \alpha 1$ contents and in glutamate and GABA levels in the center mean \pm SEM. Glutamate $(E)$ and GABA ( $F$ ) levels measured with HPLC from homogenates of the lesion tissue depicted in Figure $4 A$ are shown. The asterisk denotes a significant difference $(p<0.05)$ between groups.

is accompanied over time by morphological and biochemical modifications in the surrounding area of the lesion. Over a 5 week period of recovery, sprouting of MAP-2-positive dendrite-like structures in the surround of a visual cortex ischemic lesion corresponds with an upregulation of MAP-2. Concomitant with morphological modifications, an increase in NMDAR1 protein content parallels an increase in glutamate levels in the area surrounding the lesion (after a pronounced decrease immediately after the lesion).

The enlargement of the area of cortex responding to a stimulus of a given size, as evidenced by our retinotopic mapping procedure, constitutes a mechanism by which the representation of the retinal input in the visual cortex is reorganized after a focal lesion. At the single-cell level, this corresponds to an increase in receptive field size such that parts of the visual field originally represented in the lesion area of cortex are encompassed (Eysel 
Table 1. Temporal course of amino acid levels from the lesion area

\begin{tabular}{lccc}
\hline Amino acid & Control & 1wPL & 2wPL \\
\hline Asp & $3.65 \pm 0.44$ & $0.96 \pm 0.12$ & $0.98 \pm 0.019$ \\
Glu & $10.95 \pm 1.1$ & $2.93 \pm 0.40$ & $2.76 \pm 0.14$ \\
Gln & $4.84 \pm 0.27$ & $1.60 \pm 0.26$ & $1.66 \pm 0.14^{*}$ \\
Gly & $3.27 \pm 0.15$ & $2.58 \pm 1.56$ & $5.60 \pm 0.95^{*}$ \\
Tau & $3.28 \pm 1.23$ & $0.29 \pm 0.04$ & $2.20 \pm 1.35$ \\
Ala & $1.10 \pm 0.94$ & $1.24 \pm 0.23$ & $0.31 \pm 0.02$ \\
GABA & $1.76 \pm 0.06$ & $0.46 \pm 0.10$ & $0.98 \pm 0.06$ \\
\hline
\end{tabular}

Control refers to homogenates of area 17 from a nonlesioned animal. The mean group data $\pm \mathrm{SE}(n=3)$ are shown. ${ }^{*} p<0.03$ (comparisons were made between 1 and $5 \mathrm{wPL}$ ).

and Schweigart, 1999; Schweigart and Eysel, 2002). A similar expansion of cortical receptive fields after focal retinal lesions is well documented (Kaas et al., 1990; Das and Gilbert, 1995a,b) and has been attributed to axonal sprouting of horizontal connections within the visual cortex (Gilbert and Wiesel, 1985; Darian-Smith and Gilbert, 1994, 1995).

Here, we correlated in time the reorganization of the visual cortical maps after cortical lesions with changes in cellular markers of plasticity that have been associated with mechanisms underlying functional reorganization after injury. Some of these mechanisms include dendritic and axonal sprouting, synaptogenesis, and altered synaptic efficacy (Kaas, 1991; Buonomano and Merzenich, 1998).

Cytoskeletal modifications require MAPs, such as MAP-2. Suppression of MAP-2 expression in cultured neurons inhibits neurite outgrowth and reduces neurite number (Caceres et al.,1992; Sharma et al., 1994), suggesting that MAP-2-mediated regulation of microtubules is important for dendrogenesis. MAP-2 immunoreactivity (MAP-2-IR) has been considered a suitable marker for dendrites based on experimental evidence that closely correlates dendritic growth with an increase in MAP2-IR (Philpot et al., 1997; Sanchez et al., 2000; Bury and Jones; 2002). MAP-2 has been shown to be absent in injured neurons (Arias et al., 1997). Our data also show that at 1wPL MAP-2immunopositive structures have disappeared from the core of the lesion. The amount of MAP-2 immunolabeling changed gradually over time and correlated with modifications in the contents of GFAP-immunopositive astrocytes. After 5wPL, MAP-2immunopositive fibers were not only found in the boundary zone of the ischemic center but in closest proximity to the lesion core, where the glial scar (which lines the wall of the lesion) was predominant. At every time point studied, astrocytes surrounding the lesion core were anisomorphic. However, the density of the gliotic scar diminished over time, which may be partially related to the decrease in astrocytic division and migration toward the lesion area (Bignami and Dahl, 1995). Previous studies have shown that MAP-2-IR increases after cortical damage with a similar time course as that reported here (Bidmon et al., 1998; Li et al., 1998). However, to our knowledge, this is the first study showing localization of reactive astroglia mixed with dendriticlike structures, as morphological evidence of sprouting, as early as 2 weeks after an ischemic lesion.

In agreement with immunohistochemical data, immunoblot results show a time-dependent increase of MAP-2 content in the area surrounding the lesion. Because Western blot analysis was performed from total protein contents, MAP-2 upregulation reflects an increase in protein synthesis over time and discards the possibility that MAP-2 was redistributed in areas other than dendrites. The gradual upregulation in protein contents correlates with the presence of dendritic-like structures and with the observed functional plasticity reported here and in a previous study
(Zepeda et al., 2003) and suggests MAP-2 synthesis, leading to dendritic sprouting, as a possible mechanism by which cortical reorganization may occur. Supporting this conclusion, NeuN immuolabeling indicated that the number of neurons did not change between 2 and 5wPL, whereas an increase in the density of MAP2-positive fibers was observed.

The role of axonal sprouting in CNS regeneration is still controversial; however, some studies have correlated axonal elongation with an upregulation of GAP-43. Recent reports (Stroemer et al., 1995; Li et al., 1998; Carmichael et al., 2001; Carmichael and Chesselet, 2002) describe an increase in GAP-43 immunoreactivity from day 3 until day 14 postlesion. Our results also show an increase in GAP-43 contents at $2 \mathrm{wPL}$, but this is followed by a decline in protein levels toward 5wPL (Stroemer et al., 1995). As suggested previously, GAP-43 may be involved in the initiation of axonal growth, whereas the full regenerative program is accomplished by another set of proteins (Strata et al., 1999). In contrast, axonal sprouting cannot solely be determined on GAP-43 levels alone, because GAP-43 is not a rigid marker of axonal sprouting (Szele et al., 1995). After cortical and peripheral lesions, axonal sprouting has been shown to occur in local circuit connections, but no axonal remodeling was detected at the thalamocortical level (Darian-Smith and Gilbert, 1994; Carmichael et al., 2001). Thus, although the gradual increase in MAP-2 expression in our model correlates more evidently in time with functional reorganization than GAP-43 expression, we cannot rule out the possibility that axonal sprouting may take place at some point in the recovery process.

In addition to morphological modifications occurring in the surrounding area of the lesion, neurochemical transmission changes have been proposed to play a role in reorganization of cortical maps. A variety of studies have suggested that the balance between excitation and inhibition modulate plastic responses in the CNS after peripheral or central injuries (Schiene et al., 1996; Neumann-Haefelin et al., 1998; Que et al., 1999a,b; Arckens et al., 2000; Redecker et al., 2002), but only few studies (Qu et al., 2003) correlate time-dependent changes in neurotransmitter systems with functional recovery, which may reflect biochemical adjustments involved in shaping neuronal receptive fields during functional reorganization. Reduction of cortical inhibitory tone through a decrease in the availability of GABA or an increase in glutamate transmission have been suggested as possible mechanisms underlying functional reorganization (Garraghty et al., 1991). Changes at the amino acid level could reflect the activation of adaptive presynaptic mechanisms, whereas modifications in the receptor subunits explored in this study could be related to postsynaptic responses that lead to changes in the excitatory/ inhibitory neurotransmission balance. These changes differed not only with regard to their time course but also in magnitude. The upregulation of NR1, the mandatory subunit of the NMDA receptor, between $1 \mathrm{wPL}$ and $5 \mathrm{wPL}$ was paralleled by a substantial 
recovery in glutamate levels. Our results extend previously existing data that have shown increased excitability during functional recovery in the vicinity of cortical lesions (Schiene et al., 1996; Hagemann et al., 1998). We observed that the lowest levels in NR1 coincide in time with the largest functionally silent region produced by the lesion (1wPL) and that the increase in NR1 at $2 \mathrm{wPL}$ and the additional rise by $5 \mathrm{wPL}$ correlate well in time with the functional reorganization process (Zepeda et al., 2003). Thus, as shown previously for peripheral lesions (Myers et al., 2000), it is likely that the NMDA receptor participates in the synaptic changes that contribute to functional reorganization after focal cortical lesions. An increase in NMDA receptor activation could, on the one hand, mediate an increase in neuronal excitability but could also contribute to morphological modifications particularly associated with cytoskeletal changes (Montoro et al., 1993). Furthermore, the parallel increase in glutamate levels probably reflects excitatory adaptive changes at the presynaptic and postsynaptic levels. The increase of excitatory amino acid levels seems to be specific because contents of other nontransmitter amino acids, which were measured in parallel, did not change in a similar magnitude. There is evidence that changes in the GABAergic system occur after ischemic and other lesion protocols (Domann et al., 1993; Mittmann et al., 1994; Schiene et al., 1996; Neumann-Haefelin et al., 1998). Interestingly, in our model, GABA levels diminished and remained reduced after 1, 2, and $5 \mathrm{wPL}$ in agreement with previous reports (Domann et al., 1993; Mittmann et al., 1994; Neumann-Haefelin et al., 1998), whereas $\mathrm{GABA}_{\mathrm{A}} \alpha 1$ receptor subunit contents recovered almost to control levels after 2 and 5wPL. Taken together, our results show that during reorganization of retinotopic maps after an ischemic lesion, content of GABA is reduced and that although the density of postsynaptic $\mathrm{GABA}_{\mathrm{A}} \alpha 1$ increases, the $\mathrm{GABA}_{\mathrm{A}}$ receptor may not be saturated, resulting in reduced GABAergic inhibition. Reduced GABA levels in visual cortex after several peripheral manipulations have been reported previously (Jones, 1993). It has also been suggested that GABA metabolism can determine inhibitory synaptic strength and that presynaptic GABA content is a regulated mechanism for synaptic plasticity (Engel et al., 2001).

In conclusion, our results suggest that during functional recovery between 2 and $5 \mathrm{wPL}$ differential changes between GABAergic and glutamatergic transmission occur. In addition, modifications in the dendritic structure in the surrounding area of the lesion may contribute synergistically to biochemical adjustments, thus providing the basis for the reorganization of the cortical maps after focal ischemic damage. Our results also provide valuable information about "windows of opportunity" in which therapeutic interventions may affect the physiological process underlying functional reorganization.

\section{References}

Arckens L, Schweigart G, Qu Y, Wouters G, Pow DV, Vandesande F, Eysel UT, Orban GA (2000) Cooperative changes in GABA, glutamate and activity levels: the missing link in cortical plasticity. Eur J Neurosci 12:4222-4232.

Arias C, Arrieta I, Massieu L, Tapia R (1997) Neuronal damage and MAP2 changes induced by the glutamate transport inhibitor dihydrokainate and by kainate in rat hippocampus in vivo. Exp Brain Res 116:467-476.

Bidmon HJ, Jancsik V, Schleicher A, Hagemann G, Witte OW, Woodhams P, Zilles K (1998) Structural alterations and changes in cytoskeletal proteins and proteoglycans after cortical ischemia. Neuroscience 82:397-420.

Bignami A, Dahl D (1995) Gliosis. In: Neuroglia (Kettenmann H, Ransom BR, eds), pp 843-858. New York: Oxford UP.

Bonhoeffer T, Grinvald A (1993) The layout of iso-orientation domains in area 18 of cat visual cortex: optical imaging reveals a pinwheel-like organization. J Neurosci 13:4157-4180.

Bonhoeffer T, Grinvald A (1996) Optical imaging based on intrinsic signals. The methodology. In: Brain mapping: the methods (Toga A, Mazziota J, eds), pp 55-97. London: Academic.

Buonomano DV, Merzenich MM (1998) Cortical plasticity: from synapses to maps. Annu Rev Neurosci 21:149-186.

Bury SD, Jones TA (2002) Unilateral sensorimotor cortex lesions in adult rats facilitate motor skill learning with the "unaffected" forelimb and training-induced dendritic structural plasticity in the motor cortex. J Neurosci 22:8597-8606.

Caceres A, Mautino J, Kosik KD (1992) Suppression of MAP2 in cultured cerebellar macroneurons inhibits minor neurite formation. Neuron 9:607-618.

Carmichael ST (2003) Plasticity of cortical projections after stroke. Neuroscientist 9:64-75.

Carmichael ST, Chesselet MF (2002) Synchronous neuronal activity is a signal for axonal sprouting after cortical lesions in the adult. J Neurosci 22:6062-6070.

Carmichael ST, Wei L, Rovainen CM, Woolsey TA (2001) New patterns of intracortical projections after focal cortical stroke. Neurobiol Dis 8:910-922.

Castro MA, Borrell J (1995) Functional recovery of forelimb response capacity after forelimb primary motor cortex damage in the rat is due to the reorganization of adjacent areas of the cortex. Neuroscience 68:793-805.

Coq JO, Xerri C (1999) Acute reorganization of the forepaw representation in the rat SI cortex after focal cortical injury: neuroprotective effects of piracetam treatment. Eur J Neurosci 11:2597-2608.

Darian-Smith C, Gilbert CD (1994) Axonal sprouting accompanies functional reorganization in adult cat striate cortex. Nature 368:737-740.

Darian-Smith C, Gilbert CD (1995) Topographic reorganization in the striate cortex of the adult cat and monkey is cortically mediated. J Neurosci 15:1631-1647.

Das A, Gilbert CD (1995a) Receptive field expansion in adult visual cortex is linked to dynamic changes in strength of cortical connections. J Neurophysiol 74:779-792.

Das A, Gilbert CD (1995b) Long-range horizontal connections and their role in cortical reorganization revealed by optical recording of cat primary visual cortex. Nature 375:780-784.

Dijkhuizen RM, Singhal AB, Mandevill JB, Wu O, Halpern EF, Finklestein SP, Rosen BR, Lo EH (2003) Correlation between brain reorganization, ischemic damage, and neurologic status after transient focal cerebral ischemia in rats: a functional magnetic resonance imaging study. J Neurosci 23:510-517.

Domann R, Hagemann G, Kraemer M, Freund HJ, Witte OW (1993) Electrophysiological changes in the surrounding brain tissue of photochemically induced cortical infarcts in the rat. Neurosci Lett 155:69-72.

Engel D, Pahner I, Schulze K, Frahm C, Jarry H, Ahnert-Hilger G, Draguhn A (2001) Plasticity of rat central inhibitory synapses through GABA metabolism. J Physiol (Lond) 535:473-482.

Eysel UT, Schweigart G (1999) Increased receptive field size in the surround of chronic lesions in the adult cat visual cortex. Cereb Cortex 9:101-109.

Florence SL, Kaas JH (1995) Large-scale reorganization at multiple levels of the somatosensory pathway follows therapeutic amputation of the hand in monkeys. J Neurosci 15:8083-8095.

Garraghty PE, LaChica EA, Kaas JH (1991) Injury-induced reorganization of somatosensory cortex is accompanied by reductions in GABA staining. Somatosens Mot Res 8:347-354.

Geddes JW, Wood JD (1984) Changes in the amino acid content of nerve endings (synaptosomes) induced by drugs that alter the metabolism of glutamate and G-aminobutyric acid. J Neurochem 42:16-24.

Gilbert CD, Wiesel TN (1985) Intrinsic connectivity and receptive field properties in visual cortex. Vision Res 25:365-374.

Hagemann G, Redecker C, Neumann-Haefelin T, Freund HJ, Witte OW (1998) Increased long-term potentiation in the surround of experimentally induced focal cortical infarction. Ann Neurol 44:255-258.

Jones EG (1993) GABAergic neurons and their role in cortical plasticity in primates. Cereb Cortex 3:361-372.

Jones TA, Schallert T (1992) Overgrowth and prunning of dendrites in adult rats recovery from neocortical damage. Brain Res 581:156-160.

Jones TA, Kleim JA, Greenough WT (1996) Synaptogenesis and dendritic growth in the cortex opposite unilateral sensoriomotor cortex damage in 
adult rats: a quantitative electron microscopic examination. Brain Res 733:142-148.

Kaas JH (1991) Plasticity of sensory and motor maps in adult mammals. Annu Rev Neurosci 14:137-167.

Kaas JH, Krubitzer LA, Chino YM, Langston AL, Polley EH, Blair N (1990) Reorganization of retinotopic cortical maps in adult mammals after lesions of the retina. Science 248:229-231.

Laemmli UK (1970) Cleavage of structural proteins during the assembly of the head of bacteriophage T4. Nature 227:680-685.

Li Y, Jiang N, Powers C, Chopp M (1998) Neuronal damage and plasticity identified by microtubule-associated protein 2 , growth associated protein 43 , and cyclin D1 immunoreactivityafter focal cerebral ischemia in rats. Stroke 29:1972-1980.

Mittmann T, Eysel UT (2001) Increased synaptic plasticity in the surround of visual cortex lesions in rats. NeuroReport 12:3341-3347.

Mittmann T, Luhmann H, Schmidt-Kastner R, Eysel U, Weigel H, Heinemann U (1994) Lesion-induced transient supression of inhibitory function in rat neocortex in vitro. Neuroscience 60:891-906.

Montoro RJ, Diaz-Nido J, Avila J, Lopez-Barneo J (1993) N-methyl-Daspartate stimulates the dephosphorylation of the microtubule-associated protein 2 and potentiates excitatory synaptic pathways in the rat hippocampus. Neuroscience 54:859-871.

Mullen RJ, Buck CR, Smith AM (1992) NeuN, a neuronal specific nuclear protein in vertebrates. Development 116:201-211.

Myers WA, Churchill JD, Muja N, Garraghty PE (2000) Role of NMDA receptors in adult primate cortical somatosensory plasticity. J Comp Neurol 418:373-382.

Neumann-Haefelin T, Staiger JF, Redecker C, Zilles K, Fritschy JM, Mohler H, Witte OW (1998) Immunohistochemical evidence for dysregulation of the GABAergic system ipsilateral to photochemically induced cortical infarcts in rats. Neuroscience 87:871-879.

Nudo RJ, Wise BM, SiFuentes F, Milliken GW (1996a) Neural substrates for the effects of rehabilitative training on motor recovery after ischemic infarct. Science 272:1791-1794.

Nudo RJ, Milliken GW, Jenkins WM, Merzenich MM (1996b) Usedependent alterations of movement representations in primary motor cortex of adult squirrel monkeys. J Neurosci 16:785-807.

Peters A, Yilmaz E (1993) Neuronal organization in area 17 of cat visual cortex. Cereb Cortex 3:49-68.

Philpot BD, Lim JH, Halpain S, Brunjes PC (1997) Experience-dependent modifications in MAP2 phosphorylation in rat olfactory bulb. J Neurosci 17:9596-9604.

Qu Y, Massie A, Van der Gucht E, Cnops L, Vandenbussche E, Eysel UT, Vandesande F, Arckens L (2003) Retinal lesions affect extracellular glutamate levels in sensory-deprived and remote non-deprived regions of cat area 17 as revealed by in vivo microdialysis. Brain Res 962:199-206.

Que M, Schiene K, Witte OW, Zilles K (1999a) Widespread up-regulation of N-methyl-D-aspartate receptors after focal photothrombotic lesion in rat brain. Neurosci Lett 273:77-80.
Que M, Witte OW, Neumann-Haefelin T, Schiene K, Schroeter M, Zilles K (1999b) Changes in GABA(A) and GABA(B) receptor binding following cortical photothrombosis: a quantitative receptor autoradiographic study. Neuroscience 93:1233-1240.

Redecker C, Wang W, Fritschy JM, Witte OW (2002) Widespread and longlasting alterations in GABAA-receptor subtypes after focal cortical infarcts in rats: mediation by NMDA-dependent processes. J Cereb Blood Flow Metab 22:1463-1475.

Rijntjes M, Weiller C (2002) Recovery of motor and language abilities after stroke: the contribution of functional imaging. Prog Neurobiol 66:109-122.

Rouiller EM, Yu XH, Moret V, Tempini A, Wiesendanger M, Liang F (1998a) Dexterity in adult monkeys following early lesion of the motor cortical hand area: the role of cortex adjacent to the lesion. Eur J Neurosci 10:729-740.

Sanchez C, Diaz-Nido J, Avila J (2000) Phosphorylation of microtubuleassociated protein 2 (MAP-2) and its relevance for the regulation of the neuronal cytoskeleton function. Prog Neurobiol 61:133-168.

Schiene K, Bruehl C, Zilles K, Qu M, Hagemann G, Kraemer M, Witte OW (1996) Neuronal hyperexcitability and reduction of GABAA-receptor expression in the surround of cerebral photothrombosis. J Cereb Blood Flow Metab 16:906-914.

Schweigart G, Eysel UT (2002) Activity-dependent receptive field changes in the surround of adult cat visual cortex lesions. Eur J Neurosci 15:1585-1596.

Sharma N, Kress Y, Shafit-Zagardo B (1994) Antisense MAP-2 oligonucleotides induce changes in microtubule assembly and neuritic elongation in pre-existing neurites of rat cortical neurons. Cell Motil Cytoskeleton 27:234-247.

Strata P, Buffo A, Rossi F (1999) Mechanisms of axonal plasticity. Arch Ital Biol 137:181-192.

Stroemer RP, Kent TA, Hulsebosch CE (1995) Neocortical neural sprouting, synaptogenesis, and behavioral recovery after neocortical infarction in rats. Stroke 26:2135-2144.

Szele FG, Alexander C, Chesselet MF (1995) Expression of molecules associated with neuronal plasticity in the striatum after aspiration and thermocoagulatory lesions of the cerebral cortex in adult rats. J Neurosci 15:4429-4448.

Watson BD, Dietrich WD, Busto R, Wachtel MS, Ginsberg MD (1985) Induction of reproducible brain infarction by photochemically initiated thrombosis. Ann Neurol 17:497-504.

Zepeda A, Montiel T, Brailowsky S (1999) Functional recovery from cortical hemiplegia in the rat: Effects of a callosotomy. J Neurotrauma 16:267-271.

Zepeda A, Vaca L, Arias C, Sengpiel F (2003) Reorganization of visual cortical maps after focal ischemic lesions. J Cereb Blood Flow Metab 23:811-820. 